\title{
THE NEW INJECTOR AND STORAGE RING FOR THE MAX-LABORATORY
}

\author{
Sverker Werin*, Åke Andersson, Mikael Eriksson, Mattias Georgsson, \\ Greg LeBlanc, Lars-Johan Lindgren, Erik Wallén \\ MAX-lab, P.O. Box 118, S-221 00 Lund, Sweden \\ $\underline{\text { Sandra Biedron }}$
}

Advanced Photon Source, Argonne National Laboratory, Argonne, IL 60439

\begin{abstract}
In December 1998 the FRN - The Swedish Council for Planning and Coordination of Research - decided to fund a new injector and storage ring for the MAX-laboratory. The system will consist of a 50-MeV linac, a $600-\mathrm{MeV}$ booster synchrotron, and a 600-MeV storage ring for VUV undulator beamlines. The system will replace an old 100-MeV racetrack microtron and will inject the two existing storage rings: the 550-MeV MAX I and the 1.5GeV MAX II, as well as the new 600-MeV storage ring. The linac injector will also be designed with intentions to provide electrons for a future infrared free-electron laser (IR-FEL) facility. The detailed design of the system began in January 1999 with a planned first beam in the summer of 2001.
\end{abstract}

\section{OVERVIEW}

The current MAX-lab accelerator system [1] consists of a $100-\mathrm{MeV}$ racetrack microtron used as injector for the $550-\mathrm{MeV}$ storage ring, MAX I. MAX I is able to store electrons for synchrotron radiation production, stretch

Table 1. Pre-injector system

\begin{tabular}{|lll|}
\hline GUN & Thermionic rf gun \\
\hline & Energy & $\sim 2 \mathrm{MeV}$ \\
\hline & Micropulse length & $\leq 10 \mathrm{ps}$ \\
\hline rf frequency & $3 \mathrm{GHz}$ \\
\hline Charge/micropulse & $0.2 \mathrm{nC}$ \\
\hline & Normalised emittance & $15 \mathrm{~mm} \mathrm{mrad}$ \\
\hline LINAC & Energy range & $25-50 \mathrm{MeV}$ \\
\hline & Macropulse current & $10-100 \mathrm{~mA}$ \\
\hline Rep. rate & $1-50 \mathrm{~Hz}$ \\
\hline rf frequency & $3 \mathrm{GHz}$ \\
\hline Max. rf power & $35 \mathrm{MW}$ \\
\hline Normalised emittance & $15 \mathrm{~mm}$ mrad \\
\hline \multicolumn{2}{c}{ Most values are preliminary }
\end{tabular}

* E-mail: sverker.werin@maxlab.lu.se them in pulse-stretcher mode for nuclear physics research, or serve as an injector supplying a 500-MeV beam to MAX II. MAX II, used exclusively for synchrotron radiation production, accepts beam from MAX I and is able to further accelerate it to $1.5 \mathrm{GeV}$.

Although the injector system provides a quality beam, the aging, twenty-year old, radiation damaged racetrack microtron needs replacement to ensure reliable operation in the future.

A new injector system is being designed but has a number of constraints for the various modes of operation. These include,

- Injection into the MAX II storage ring without entering MAX I.

- Full energy injection into MAX I (550 MeV).

- Increased energy of MAX I in pulse-stretcher mode (from 100 to $250 \mathrm{MeV}$ ).

Also, additional desires arose, including

- Additional space for VUV-beamlines.

- Drive beam for an IR-FEL.

- Capabilities for a storage ring (SR) UV-FEL.

The injector upgrade concept, presented to the FRN The Swedish Council for Planning and Coordination of Research, consists of a thermionic electron gun, a normal-conducting 50-MeV linac, a $600-\mathrm{MeV}$ booster and, on top of the booster, a $700-\mathrm{MeV}$ storage ring. The rings both have a 33-m circumference and will be placed in an available area, between the two existing storage rings. The linac system, however, will be placed in a presently unoccupied space in the basement. 


\section{THE GUN AND LINAC-SYSTEM}

The gun and linac parameters can be found in Table 1. The linac will consist of a $3-\mathrm{GHz}$ accelerating structure identical to the ones for the Swiss Light Source (SLS) injector and the normal-conducting TESLA alternative [2]. A 35-MW klystron will feed the linac with sufficient $\mathrm{rf}$ power to accelerate $200 \mathrm{~mA}$ to $50 \mathrm{MeV}$. Until recently, it was assumed that a standard thermionic dc gun with a $500-\mathrm{MHz}$ pre-buncher and a $3-\mathrm{GHz}$ buncher would be used. Now, however, a thermionic rf gun with a magnetic compressor is under examination, since this would eliminate the need for a pre-buncher and buncher. This pathway seems most promising, since both SSRL [3] and APS [4] routinely operate with such guns.

\section{THE BOOSTER}

The booster concept was chosen as a convenient and reliable way to provide $500-\mathrm{MeV}$ electrons for the storage rings at the laboratory.

\subsection{Lattice}

A combined function four-fold structure, as illustrated in Figures 1 and 2, will be used. The quadrupoles are focussing in the horizontal direction and the dipole magnets have a gradient for vertical focussing. Sextupole components are included in the quadrupole and dipole magnets to provide a positive chromaticity. The booster lattice parameters are given in Table 2 .

Table 2. Booster parameters

\begin{tabular}{|ll|}
\hline Max energy & $600 \mathrm{MeV}$ \\
\hline Injection energy & $50 \mathrm{MeV}$ \\
\hline Circulating current & $40 \mathrm{~mA}$ \\
\hline Circumference & $\approx 30 \mathrm{~m}$ \\
\hline Straight section length & $3.1 \mathrm{~m}$ \\
\hline Mom comp factor & 0.045 \\
\hline Nat hor emittance & $31 \mathrm{nmrad}(@ 600 \mathrm{MeV})$ \\
\hline Quadrupoles & $\mathrm{L}=0.25 / 0.4 \mathrm{~m} ; \mathrm{K}: 3.998 ;$ \\
& $\mathrm{R}=2 \mathrm{~cm}$ \\
\hline Dipoles & $\mathrm{L}=1.3333 \mathrm{~m} ; \mathrm{n}: 1.8836 ;$ \\
& $\mathrm{g} / 2=1 \mathrm{~cm}$ \\
\hline Hor admittance & $26 \mathrm{~mm} \mathrm{mrad}$ \\
\hline Vertical admittance & $5 \mathrm{~mm} \mathrm{mrad}$ \\
\hline Momentum acceptance & $1 \%$ \\
\hline Rep rate & $10 \mathrm{~Hz} / 1 \mathrm{~Hz}$ \\
\hline & \multicolumn{1}{c|}{ Most values are preliminary } \\
\hline
\end{tabular}
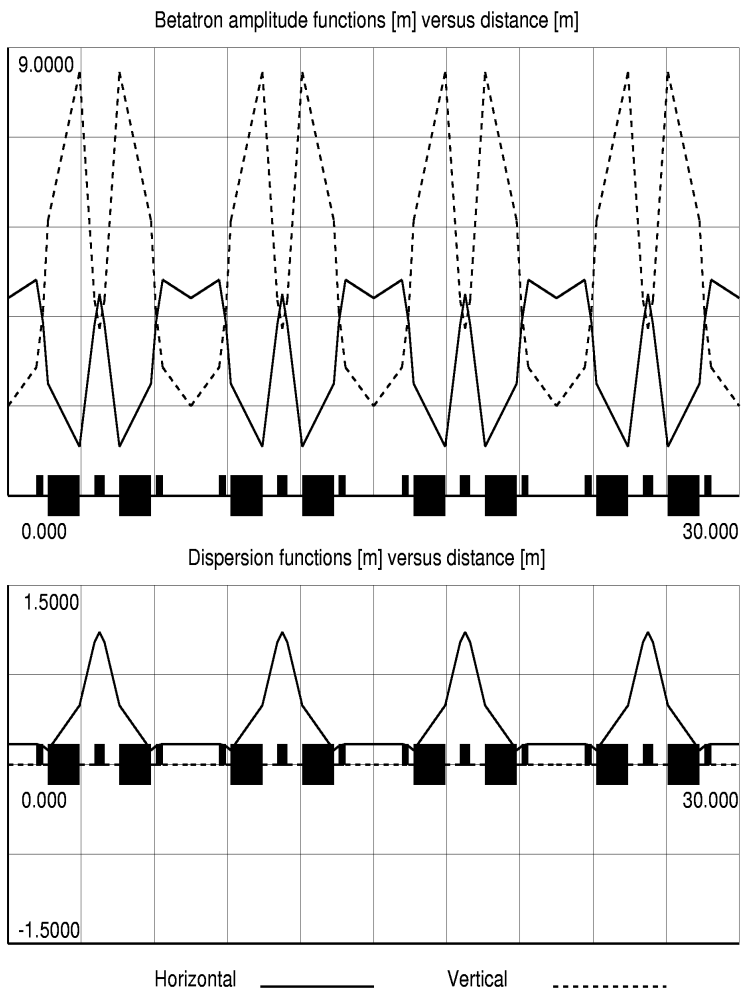

Figure 1. The lattice for both booster and storage ring.

\section{THE STORAGE RING}

The storage ring is designed to provide a simple and inexpensive way to provide additional VUV beamlines. Here, a lattice combining compactness and low emittance, also applicable to the booster, was created by allowing dispersion in the straight sections and a gradient in the bending magnets thus enhancing synchrotron radiation damping. The storage ring parameters are given in Table 3.

Since this ring has a lattice similar to the booster, it will be conveniently placed on top of and injected by the booster. Using the same girders will save space and make survey and alignment less time consuming. Also, producing a "double set" of magnets will minimize the production cost. To avoid crosstalk between the magnetic fields of the two rings, however, a separation distance of approximately $40 \mathrm{~cm}$ is necessary.

\section{OPERATION MODES}

\subsection{Injector for MAX II}

The quality of an injector for MAX II is defined by its emittance. The booster will operate at $1 \mathrm{~Hz}$ and 500 $\mathrm{MeV}$, providing significant improvement regarding both 
Table 3. Storage ring parameters

\begin{tabular}{|ll|}
\hline Operating energy & $700 \mathrm{MeV}$ \\
\hline Circulating current & $200 \mathrm{~mA}$ \\
\hline rf frequency & $100 \mathrm{MHz}$ \\
\hline rf voltage & $0.21 \mathrm{MV}$ \\
\hline Half bucket height & $1 \%$ \\
\hline Energy spread (natural) & $0.4 * 10-3$ \\
\hline Bunch length (natural) & $0.75 \mathrm{~cm}$ \\
\hline Lifetime: Touschek & $0.27 \mathrm{Ah} @ 10 \%$ coupling \\
\hline \multicolumn{1}{|c|}{ Vacuum } & $8 \mathrm{~h} @ 1 \mathrm{nTorr} \mathrm{CO}$ \\
\hline Emittance & $26 \mathrm{~nm}$ rad $($ @ $700 \mathrm{MeV})$ \\
\hline Beam size in SS & $0.35 * 0.07$ mm2 \\
\hline
\end{tabular}

the repetition rate of the injection and the injected current.

\subsection{Injector for $M A X I$}

The MAX I storage ring will be injected at the full design energy of $500 \mathrm{MeV}$ instead of the present 100 $\mathrm{MeV}$. Given the low emittance injector design, more reliable operation is predicted, even at increasingly higher currents.

\subsection{Storage ring mode}

The storage ring was designed to have the same qualities as MAX II, a full third generation light source, implying excellent stability, low coupling, long lifetimes and a low emittance. To provide painless operation, injection will be made at almost full energy.

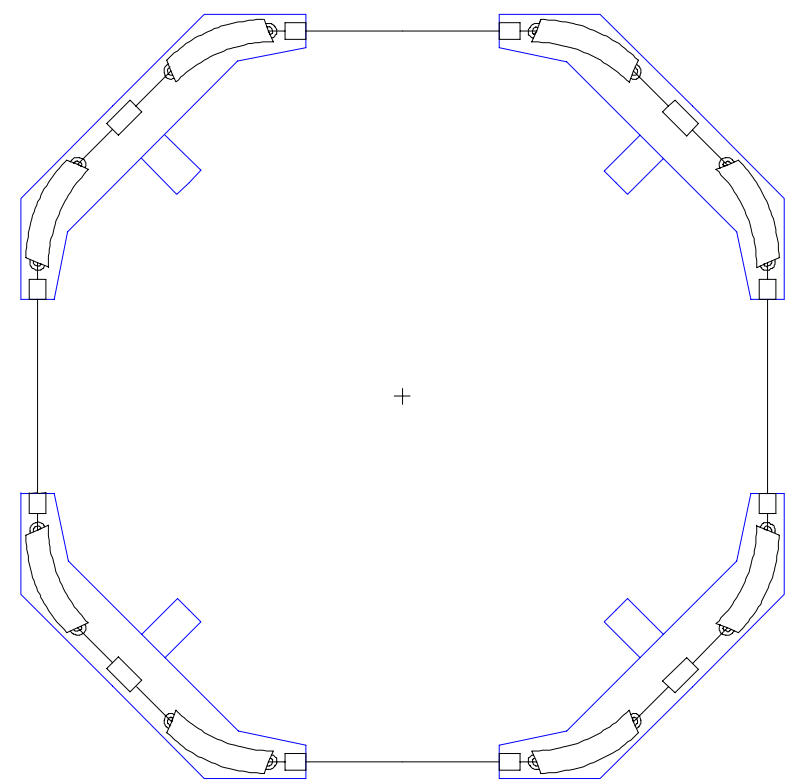

Figure 2. Layout of the two rings.

\subsection{Nuclear physics operation}

In pulse-stretcher mode, the operating energy of MAX I will be extended up to $250 \mathrm{MeV}$, at a repetition rate of $10 \mathrm{~Hz}$. Since the new injector will be able to deliver higher peak currents, new nuclear physics experiments have been proposed.

\subsection{FEL laser prospects}

The linac will allow for a future IR-FEL facility. In order to supply the $10-\mu$ s rf pulse necessary for FEL operation, however, modifications to the klystrons and/or the gun may be required. The main demands placed on an FEL injector are the low energy spread and high peak current beams.

The storage ring will also be well tuned for a UV SRFEL. This concept is presently being researched by an EU-sponsored collaboration at ELETTRA, in which MAX-lab is participating.

Neither of these two FEL concepts are included in the present funding.

\section{RADIATION SHIELDING}

The issue of radiation shielding is currently under investigation and may cause construction and/or design changes. This is due to possible structural limitations in the building intended to house the new injector system.

\section{REFERENCES}

[1] A. Andersson et al, Nucl. Instr. And Meth. A 343 (1994) 644

[2] R. Brinkman et al, (eds) "Conceptual design of a 500 $\mathrm{GeV}$ e+e- Linear Collider with Integrated X-ray Laser facility", DESY 1997-048

[3] M. Borland et al, "Performance of the $2 \mathrm{MeV}$ Microwave Gun for the SSRL $150 \mathrm{MeV}$ Linac", SLACPUB-5333, 1990

[4] J.W. Lewellen, S. Biedron, A. Lumpkin, S.V. Milton, A. Nassiri, S. Pasky, G.Travish, M. White, "Operation of the APS RF Gun," Proceedings of the XX International Linear Accelerator Conference, Chicago, Illinois, August 23-28, 1998, to be published. 